\title{
Fatigue strength evaluation of self-piercing riveted cold rolled steel joints under mixed mode loading conditions
}

\author{
KYUNG-MIN LEE ${ }^{1}$, DONG-WOON HAN ${ }^{2}$, HO-KYUNG KIM*² \\ ${ }^{1}$ Graduate School of Industry, Seoul National University of Science and Technology \\ ${ }^{2}$ Dept. of Mechanical and Automotive Engineering, Seoul National University of Science and Technology \\ 172 Kongneung-dong, Nowon-ku, Seoul, 139-722, Korea \\ *Corresponding author: kimhk@seoultech.ac.kr
}

\begin{abstract}
Fatigue strength of cross-shaped specimens of SPR joints made of SPCC was evaluated at load angles of $0^{\circ}, 45^{\circ}$, and $90^{\circ}$. For the static strength at load angles of $0^{\circ}, 45^{\circ}$, and $90^{\circ}$, the maximum loads were determined to be $4890 \mathrm{~N}, 1969 \mathrm{~N}$, and $1611 \mathrm{~N}$, respectively. Regarding for the relationship between the load amplitude and the number of cycles $\left(N_{f}\right)$, the results were $P_{a m p}=2209.3 N_{f}^{-0.014}$, $P_{a m p}=8610.8 N_{f}^{-0.199}$, and $P_{a m p}=3459.3 N_{f}^{-0.149}$ for the load angle of $0^{\circ}, 45^{\circ}$, and $90^{\circ}$, respectively. On the basis of the lifetime of $10^{6}$ cycles, the load amplitudes which correspond to the fatigue limit for load angles of $0^{\circ}, 45^{\circ}$, and $90^{\circ}$ were $38 \%, 28 \%$, and $29 \%$ of the static strength, respectively. The effective stress intensity factor was not found to be appropriate in the evaluation of the fatigue lifetime due to the different fatigue fracture behavior of these specimens.
\end{abstract}

Keywords: SPR joint, Fatigue strength, Equivalent stress intensity factor, Mixed mode loading

\section{INTRODUCTION}

Recently, the automobile industry has been actively working to make their automobiles lighter in order to improve the fuel efficiency of automobiles. As a means of reducing the weight of automobiles, lightweight materials with excellent mechanical properties are frequently used, including metallic materials such as aluminum, magnesium alloys, high strength steel, and others such as carbon-fiber-reinforced composites, and engineered plastics. In addition, for the application of these lightweight materials, many studies have been recently conducted on various bonding methods of these materials.

In general, spot welding is widely used as a joint method for vehicle bodies. However, it is difficult to apply spot welding to the joints of materials of different types, such as a joint between aluminum and steel materials, due to the considerable differences in their melting points. Further, when bonding composite materials or plastics with steel materials, spot welding (a type of resistance welding) cannot be applied due to the nonconductivity of composite materials and plastics. Therefore, there is high demand for joining technologies which can be used with various materials of different types or with those to which spot welding cannot be easily applied. As one such technology, the self-piercing riveting (SPR) method is gaining much attention.

The fatigue strength of the SPR joints has been investigated by a number of authors for a number of materials [1-5]. For example, Fu and Mallick [1] examined the static and fatigue strengths of self-piercing rivet joints in aluminum alloy sheets. They observed that while the static strength of the self-piercing rivet joint was influenced by riveting force, the fatigue strength was not influenced by the riveting force. Huang et al. [2] reported that the fatigue limit of tensile-shear SPR joint specimens was approximately $40 \%$ of its static strength. Iyer et al. [3] reported that the fatigue and static strengths of double-rivet SPR joints were strongly dependent on the piercing direction of the rivets. Xing et al. [4] investigated the static and fatigue strength of multiple-rivet SPR joints. They reported that these levels are influenced by the rivet number and rivet distribution pattern.

Thus far, many studies have been conducted regarding parts joined through the SPR method. However, research remains in sufficient with regard to evaluations of the fatigue strength of the SPR specimens at different load modes. Typically, to measure the fatigue lifetime and fatigue strength of SPR joints, the tensileshear, cross-tension, or coach-peel test specimens are used for the evaluation. In most cases, when evaluating the fatigue strength of SPR joints, the load amplitude is used as a parameter. However, in the case of the load amplitude, an accurate comparison is difficult when the test specimens are of different sizes, widths, or shapes. Therefore, it is necessary to develop a unified parameter which can be used for evaluations of the fatigue strengths of SPR joints regardless of the shapes and sizes of the test specimens. 
In this study, only a cross-shaped specimen will be used for SPR joints to measure the fatigue strength in various load conditions by varying the loading angles using a mixed mode load jig. To do this, cross-shape specimens made of a cold rolled steel sheet at load angles of $0^{\circ}, 45^{\circ}$, and $90^{\circ}$ will be applied to evaluate the static strength and the fatigue strength of specimens through monotonic and fatigue tests. Meanwhile, the stress intensity factor is used for evaluations of the fatigue lifetimes of the specimens for the load angles.

\section{EXPERIMENTAL PRocedURES}

\subsection{SPR Specimen}

In this study, SPCC cold rolled steel was used as the material of the SPR joints. As shown in Fig. 1, a crossshaped specimen, similar to the cross-tension specimens used in spot welding, was prepared. For the rivets, the C50541 type by Henrob Ltd. was used. This type consists of medium carbon steel (0.35 wt.\%) with an aluminum surface treatment (Almac). Both the diameter and length of the shank of the rivet were $5.3 \mathrm{~mm}$.

The bonding strengths of SPR joints vary greatly according to the dimensions such as the thickness of the sheets, the diameter of the rivets, the shape of a die used, as well as the punch load at the time of riveting. In this study, upper and lower sheets with thicknesses of $1.5 \mathrm{~mm}$ were used. All of the SPR specimens for fatigue testing were prepared for a punch load of $33.32 \mathrm{kN}$, which determined the optimal punch load based on the use of the specimens, as shown Fig. 2.

In order to evaluate the mechanical properties of SPR joints, a tensile test was carried out by producing tensile specimens. Fig. 3 shows the stress-strain curve as a result of the tensile test, and Table 1 describes the material property values.

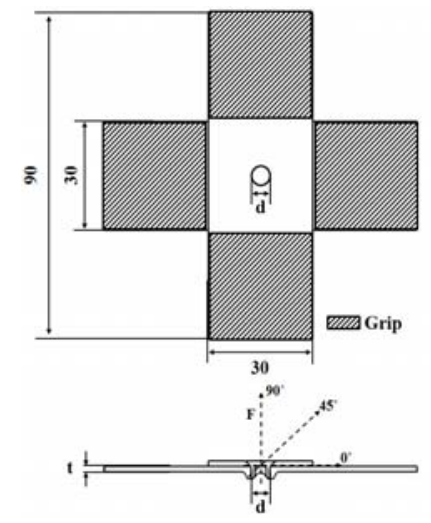

Fig. 1 Geometries and dimensions of the cross-shaped SPR specimens

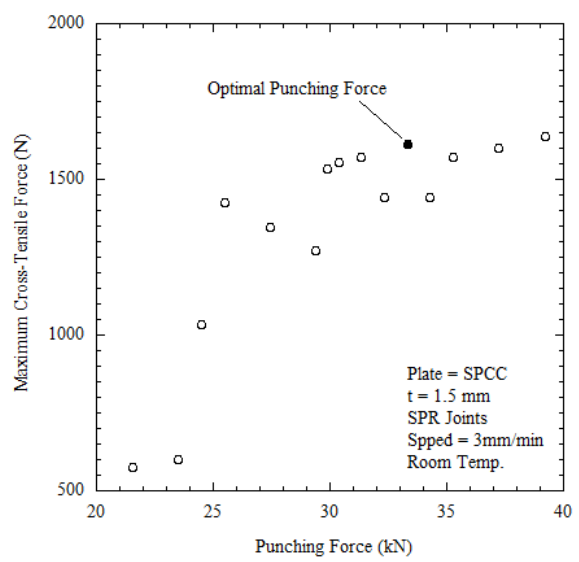

Fig. 2 Punching force against maximum cross-tensile strength for SPR specimens

Table 1 Mechanical properties of the SPCC steel sheet

\begin{tabular}{|c|c|c|c|}
\hline Material & $\sigma_{\mathrm{u}}(\mathrm{MPa})$ & $\sigma_{\mathrm{y}}(\mathrm{MPa})$ & Elong. $(\%)$ \\
\hline SPCC & 401.3 & 166.1 & 36 \\
\hline
\end{tabular}




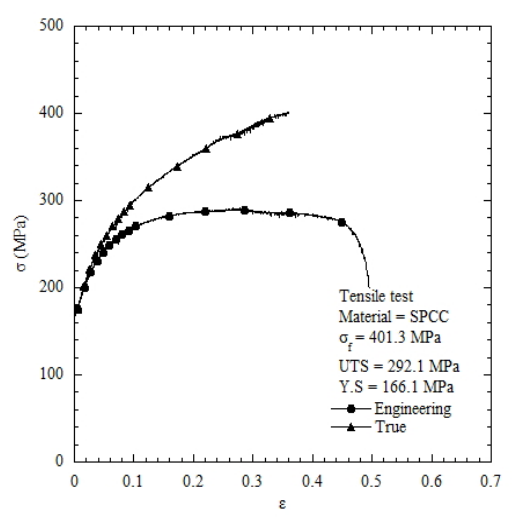

Fig. 3 Tensile stress-strain curve for the SPCC steel sheet

A mixed-mode test jig was designed, as shown in Figs. 4 and 5, in order to conduct a fatigue test at load angles of $0^{\circ}, 45^{\circ}$ and $90^{\circ}$ using a cross-shaped test specimen. When the load angle is $0^{\circ}$, it is similar to a load on a tensile-shear load of a spot welding specimen. When the load angle is $90^{\circ}$, it is very similar to the crosstension load of a spot welding specimen. In order to evaluate the monotonic and fatigue strengths of SPR joints, a hydraulic universal testing machine (Instron 8516) was used. The fatigue test was performed by applying a repeated load in the sine wave form with a stress ratio $\left(R=P_{\min } / P_{\max }\right)$ of 0.1 within a frequency range of 2 to 5 $\mathrm{Hz}$.

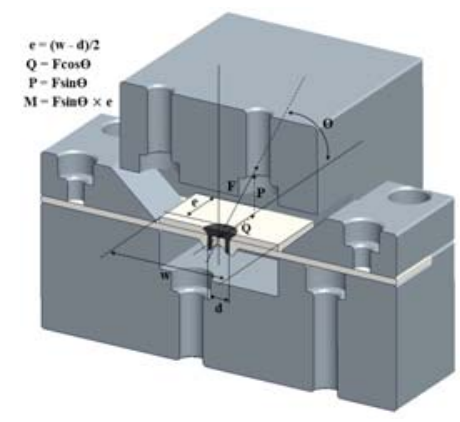

Fig. 4 Resolved components P, Q and M at the SPR joint for a general applied load F

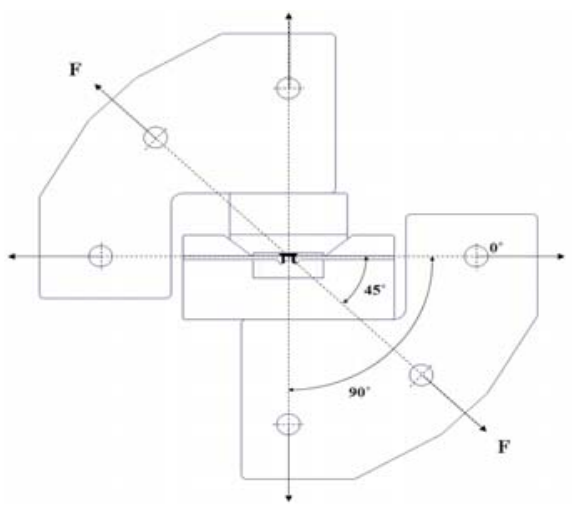

Fig. 5 Loading angle for the SPR joint

\section{EXPERIMENTAL RESULTS AND DISCUSSION}

Fig. 6 shows the static force and displacement as a result of the monotonic strength testing, where the load angles of $0^{\circ}, 45^{\circ}$ and $90^{\circ}$ were applied to the cross-shaped SPR specimens. The maximum loads for the load angles of $0^{\circ}, 45^{\circ}$ and $90^{\circ}$ were $4890 \mathrm{~N}, 1969 \mathrm{~N}, 1611 \mathrm{~N}$, respectively. In addition, it was observed that after reaching the maximum points, separation between the upper and lower sheets took place. As the load angle increased from $0^{\circ}$ to $45^{\circ}$ and to $90^{\circ}$, the strength decreased by $60 \%$ and $67 \%$, respectively. As the load angles increased, it is believed that the strength was affected by the moment at the SPR rivet caused by the load at both ends of the 
specimen.

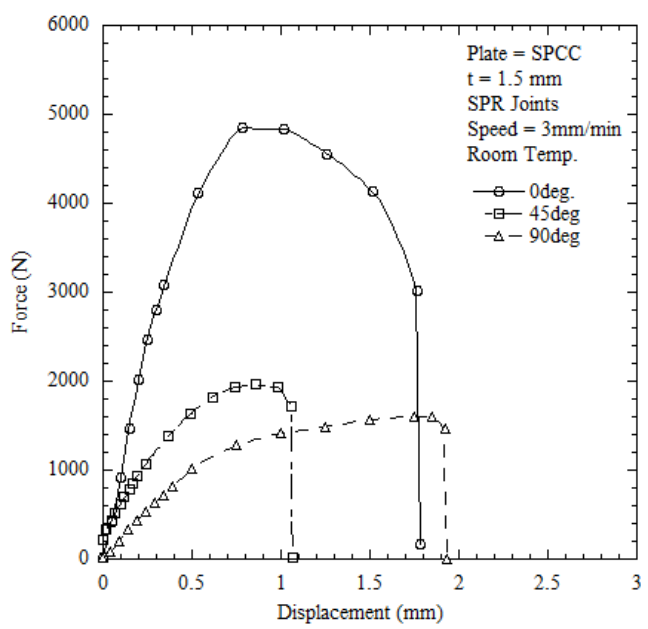

Fig. 6 Comparison of the static load versus the displacement curves of SPR specimens at different loading angles

A fatigue test of a cross-shaped specimen was conducted for the load angles of $0^{\circ}, 45^{\circ}$ and $90^{\circ}$ while varying the load amplitudes. The occurrence of fatigue failure was determined to be the time point when a crack of approximately $5 \mathrm{~mm}$ was observed around the riveting area. Fig. 7 shows the relationship between the load amplitude $\left(\mathrm{P}_{\mathrm{amp}}\right)$ and the fatigue lifetime for the load angles of $0^{\circ}, 45^{\circ}$ and $90^{\circ}$.

The relationship between the load amplitude and the number of cycles (N) was $P_{a m p}=2209.3 N_{f}^{-0.014}$ for the specimen tested at a load angle of $0^{\circ}, P_{a m p}=8610.8 N_{f}^{-0.199}$ for the specimen tested at a load angle of $45^{\circ}$, and $P_{a m p}=3459.3 N_{f}^{-0.149}$ in the case of the specimen tested at a load angle of $90^{\circ}$. Regarding the load amplitude, which corresponds to the fatigue limit, the corresponding values were $1821 \mathrm{~N}, 551 \mathrm{~N}$, and $442 \mathrm{~N}$ for the load angles of $0^{\circ}, 45^{\circ}$ and $90^{\circ}$ based on a $10^{6}$ cycle lifetime. This corresponds to $37 \%$ of the static strength $(\mathrm{P}=4890 \mathrm{~N})$ for the load angle of $0^{\circ}$. When the load angle was $45^{\circ}$, the load amplitude (fatigue limit) was about $28 \%$ of the static strength $(\mathrm{P}=1969 \mathrm{~N})$, and when the load angle was $90^{\circ}$, the load amplitude (fatigue limit) was close to $28 \%$ of the static strength $(\mathrm{P}=1611 \mathrm{~N})$.

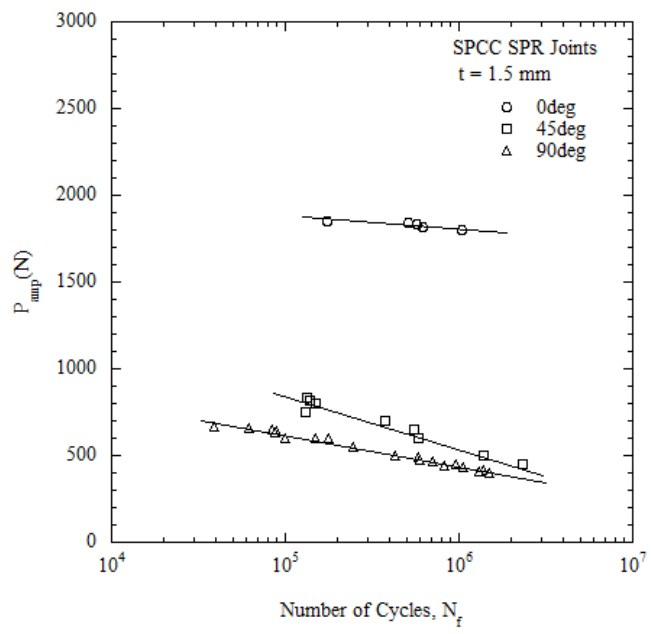

Fig. 7 Comparison of the load amplitude against number of failure cycles plots for SPR joints at different loading angles

Swellam et al. suggested the following equations for the calculation of the stress intensity factor around a spot welding nugget, where the working load F was applied [6].

$$
K_{\text {axial }}=\frac{P}{2 r \sqrt{\pi r}}
$$




$$
\begin{aligned}
& K_{\text {moment }}=\frac{3 M}{2 r^{2} \sqrt{\pi r}} \\
& K_{\text {shear }}=\frac{Q}{2 r \sqrt{\pi r}}
\end{aligned}
$$

In the above equations, " $r$ " denotes the radius of the nugget, " $p$ " represents the vertical load component of the applied load, "Q" signifies the shear load component, as shown on Fig. 4, and "M" is the bending moment at the nugget center caused by the applied load. On the other hand, the stress intensity factor at the spot welding point can be expressed as follows by applying the linear superposition principle:

$$
\begin{aligned}
& K_{I}=K_{\text {axial }}+K_{\text {moment }} \\
& K_{I I}=K_{\text {shear }} \\
& K_{\text {Ieq }}=\sqrt{K_{I}^{2}+\beta K_{I I}^{2}}
\end{aligned}
$$

Here, $K_{\text {Ieq }}$ is the equivalent stress intensity factor in mode I, and $\beta$ is a material constant for which the impacts of mode II are reflected. The material constant $\beta$ of low-carbon steel is known to be 2 .

When the angle is $90^{\circ}$ in this study, the axial-direction load $\mathrm{P}$ of the rivet shank and the moment effect caused by the cross-shaped load should be taken into consideration. The stress intensity factor $\mathrm{K}$ according to the axialdirection load P was determined based on Eq. (1) as $K_{\text {axial }}=\frac{P}{2 r \sqrt{\pi r}}$. In this equation, $\mathrm{F}=\mathrm{P}$, and " $\mathrm{r}$ " is 2.65 $\mathrm{mm}$, which corresponds to half of the rivet shank diameter of $5.3 \mathrm{~mm}$. The stress intensity factor $\mathrm{K}$ due to the moment effects caused by the cross-shaped load was determined based on Eq. (2) as $K_{\text {moment }}=\frac{3 M}{2 r^{2} \sqrt{\pi r}}$. In consideration of $M=P \times e, e=(W-d) / 2, \mathrm{~W}=30 \mathrm{~mm}$, and $\mathrm{d}=5.3 \mathrm{~mm}$, "e" was determined to be $12.35 \mathrm{~mm}$. Therefore, the stress intensity factor caused by these load effects in mode I was calculated based on Eq. (4) as $K_{I}=K_{\text {axial }}+K_{\text {moment }}$. Finally, the equivalent stress intensity factor $K_{\text {Ieq }}$ in mode I was determined based on Eq. (6) as $K_{\text {Ieq }}=K_{I}$.

When the angle is $45^{\circ}$, as shown in Fig. 4, the load F applied to the specimen consists of the axial-direction load $\mathrm{P}$ and the surface-direction load $\mathrm{Q}$ of the specimen. Load $\mathrm{P}$ and load $\mathrm{Q}$ are respectively $P=F \sin 45^{\circ}=0.707 F$ and $Q=F \cos 45^{\circ}=0.707 F$, and $K_{\text {shear }}=Q / 2 r \sqrt{\pi r}$. By applying Eqs. (1) and (2) based on load P, $K_{\text {axial }}$ and $K_{\text {moment }}$ were correspondingly determined. Meanwhile, the stress intensity factor due to load Q was determined based on Eq. (3), determining $K_{\text {shear }}$. The stress intensity factor in mode I is calculated based on Eq. (4) as $K_{I}=K_{\text {axial }}+K_{\text {moment }}$. In addition, the stress intensity factor in mode II is determined based on Eq. (5) as $K_{I I}=K_{\text {shear }}$. Finally, the equivalent stress intensity factor in mode I was determined based on Eq. (6) as $K_{\text {Ieq }}=\sqrt{K_{I}^{2}+\beta K_{I I}^{2}}=\sqrt{K_{I}^{2}+2 K_{I I}^{2}}$.

When the angle is $0^{\circ}, K_{\text {shear }}=Q / 2 r \sqrt{\pi r}$ was determined according to Eq. (3). Here, $\mathrm{F}=\mathrm{Q}$. With load Q on the plane of the specimen, a moment corresponding to about one half of the thickness is applied to such points. The stress intensity factor $\mathrm{K}$ due to the moment effects, by assuming $M=Q \times 0.5 t$, was determined according to Eq. (2) as $K_{\text {moment }}=3 M / 2 r^{2} \sqrt{\pi r}$. The stress intensity factor in mode 1 due to these moment effects was determined according to Eq. (3) as $K_{I}=K_{\text {moment }}$. Therefore, the equivalent stress intensity factor $K_{\text {Ieq }}$ in mode I was determined according to Eq. (6) as $K_{I e q}=\sqrt{K_{I}^{2}+2 K_{I I}^{2}}$.

Fig. 8 shows the fatigue lifetime results of the cross-shaped test specimens at the load angles of $0^{\circ}, 45^{\circ}$, and $90^{\circ}$ as determined by applying the stress intensity factor of Swellam et al. [6]. For comparison, this figure includes the data of tensile-shear, coach-peel and cross-tension for U.A-L.S SPR specimens, joint combination involved steel as the upper sheet and aluminum 5052 alloy as the lower sheet with the same thickness by Chung and Kim [7]. As can be seen from the data scattered over the graphs, indicating a lack of a correlation, the equivalent stress intensity factor are cannot be considered as appropriate for use in the evaluation of the fatigue strength. This behavior is due to the difference in fatigue fracture behavior in these specimens. For the specimens at $90^{\circ}$ loading angle, crack initiated between the rivet and upper sheet and propagated radially into the thickness direction of the upper sheet. However, for the specimens at the load angle of $0^{\circ}$ and $45^{\circ}$, crack 
initiated at the rivet shank and propagated through the shank, causing the final fracture of the specimen without or very small crack on the upper sheet. From this figure, the fatigue strengths of the current SPR steel joints at $90^{\circ}$ are higher than those for U.A-L.S SPR specimens. Chung and Kim [7] suggested that the fatigue endurance of the SPR joint with the combination of steel and aluminum sheets is governed by the strength of the lower sheet, which is more vulnerable to the applied load, regardless of how the steel and aluminum sheets are arranged. Even though the U.A-L.S SPR specimens have the same steel sheet as the lower sheet, these specimens exhibit lower fatigue strength than those of the current steel SPR specimens.

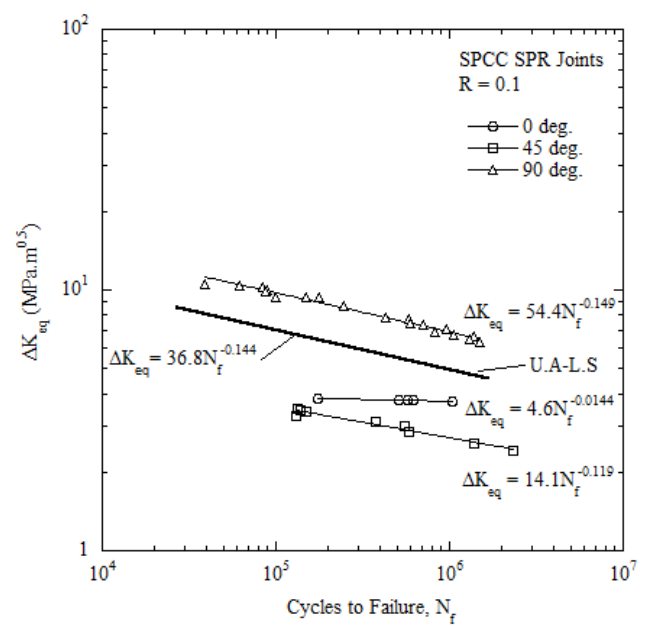

Fig. 8 Fatigue life as a function of the equivalent stress intensity factor amplitude

\section{CONCLUSION}

The fatigue strength of cross-shaped specimens of SPR joints made of SPCC was evaluated at load angles of $0^{\circ}, 45^{\circ}$, and $90^{\circ}$. The static strength was evaluated at load angles of $0^{\circ}, 45^{\circ}$, and $90^{\circ}$, and the maximum loads were measured and determined to be $4890 \mathrm{~N}, 1969 \mathrm{~N}$, and $1611 \mathrm{~N}$, respectively. After reaching the maximum points, the upper and lower sheets were separated at the jointed part. Regarding for the relationship between the load amplitude and the number of cycles $\left(N_{\mathrm{f}}\right)$, the results were $P_{a m p}=2209.3 N_{f}^{-0.014}$ for the load angle of $0^{\circ}$, $P_{a m p}=8610.8 N_{f}^{-0.199}$ for the load angle of $45^{\circ}$, and $P_{a m p}=3459.3 N_{f}^{-0.149}$ for the load angle of $90^{\circ}$. On the basis of the lifetime of $10^{6}$ cycles, the load amplitudes which correspond to the fatigue limit were $1821 \mathrm{~N}, 551 \mathrm{~N}$, and $442 \mathrm{~N}$, respectively, for load angles of $0^{\circ}, 45^{\circ}$, and $90^{\circ}$. Based on the static strength, these values correspond to $38 \%, 28 \%$, and $29 \%$ for load angles of $0^{\circ}, 45^{\circ}$, and $90^{\circ}$, respectively. When the fatigue lifetime was evaluated using fatigue test specimens at fatigue angles of $0^{\circ}, 45^{\circ}$, and $90^{\circ}$ by applying the effective stress intensity factor, the factor was not found to be appropriate in the evaluation of the fatigue lifetime due to the different fatigue fracture behavior in these specimens.

\section{ACKNOWLEDGMENT}

This study was financially supported by the Research Program funded by the Seoul National University of Science and Technology.

\section{REFERENCES}

[1] M. Fu and P.K Mallick, "Fatigue of self-piercing riveted joints in aluminum alloy 6111", Int. J. of Fatigue, vol. 25,pp. 183-189, 2003.

[2] Z. Huang, Z. Zhou, W. Huang, "Mechanical behaviors of self-piercing riveting joining dissimilar sheets", Advanced Materials Research, vol. 97-101, pp. 3932-3935, 2010.

[3] K. Iyer, S.J. Hu, F.L. Brittman, P.C. Wang, D.B. Hayden, S.P. Marin, "Fatigue of single- and double-rivet self-piercing riveted lap joints", Fatigue Fract Engng Mater Struct., vol. 28, pp. 997-1007, 2005.

[4] B. Xing, X. He, K. Zeng, Y. Wang, "Mechanical properties of self-piercing riveted joints in aluminum alloy 5052”, Int. J. Adv. Manuf. Tech. vol. 75, pp. 351-361, 2014.

[5] S. Xin, V.S. Elizabeth, A.K. Moe. "Fatigue behaviors of self-piercing rivets joining similar and dissimilar sheet metals", Int. J. of Fatigue, vol. 29, pp. 370-386, 2007.

[6] M.H. Swellam and F.V. Lawrence, "A fatigue design parameter for spot welds", Fracture Control Program Report No. 157, University of Illinois at UrbanaChampaign, 1991.

[7] C.S. Chung and H.K. Kim, "Fatigue strength of self-piercing riveted joints in lap-shear specimens of aluminum and steel sheets", Fatigue \& Fracture of Eng. Mater. \& Struct., published online, 2016. 